\title{
Commentary: Driving improvement
}

\author{
David M. Shahian, MD
}

\footnotetext{
From the Department of Surgery, and Center for Quality and Safety, Massachusetts General Hospital, Harvard Medical School, Boston, Mass.

Disclosures: Author has nothing to disclose with regard to commercial support.

Received for publication May 18, 2019; accepted for publication May 22, 2019; available ahead of print June 27, 2019.

Address for reprints: David M. Shahian, MD, Department of Surgery and Center for Quality and Safety, Massachusetts General Hospital, 55 Fruit St, Boston, MA 02114 (E-mail: dshahian@partners.org).

J Thorac Cardiovasc Surg 2020;159:1794-5

$0022-5223 / \$ 36.00$

Copyright $(2019$ by The American Association for Thoracic Surgery

https://doi.org/10.1016/j.jtcvs.2019.05.025
}

In this issue of the Journal, Worrall and colleagues ${ }^{1}$ describe a centrally governed accountability and improvement program spanning 14 cardiac surgery centers within a large health care system (Providence Health and Services). In the course of 3 years, they achieved a $50 \%$ reduction in the observed to expected mortality ratio and substantial morbidity decreases. We do not know what would have happened without these efforts, and some of the apparent improvements could simply have been regression to the mean from a single, randomly bad year (2014). We also do not know whether this exceptional performance can be sustained long term. Taken at face value, however, the Providence approach has produced admirable short- to medium-term results. What can we learn from this experience?

Historically, cardiac surgery quality improvement efforts have fallen into several major categories. The most common is feedback of risk-adjusted outcomes data to surgeons and hospitals, as exemplified by the Society of Thoracic Surgeons National Database. Ideally, these data motivate providers to initiate relevant improvement activities, and results among Society of Thoracic Surgeons Database participants ${ }^{2}$ support this hypothesis. There is limited if any central oversight or authority, however, to intervene if such improvement does not occur. In addition, some general surgery studies suggest that mere participation in a data registry does not guarantee improvement, because the latter requires special skills, ownership, and accountability. ${ }^{3-5}$

A second approach is systematic, structured peer collaboration and sharing of best practices, as introduced by the Northern New England Cardiovascular Disease Study Group in the late $1980 \mathrm{~s}^{6}$ and subsequently implemented by statewide collaboratives in Michigan ${ }^{7}$ and Virginia. ${ }^{8}$ These programs are voluntary, with centralized leadership and coordination but limited enforcement ability.

Mandatory public reporting is the third approach, implemented in New York in the late $1990 \mathrm{~s}^{9}$ and subsequently in other states; a national voluntary public reporting program

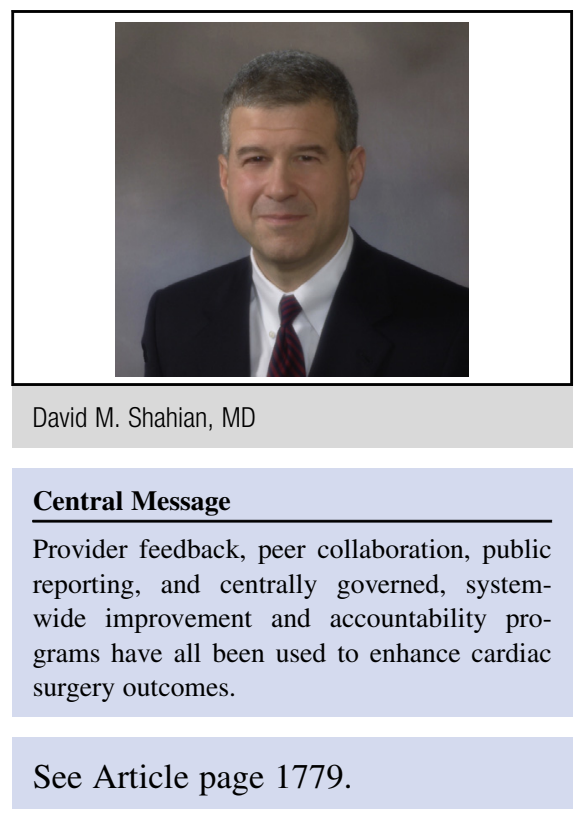

was initiated by the Society of Thoracic Surgeons in $2010 .{ }^{10}$ These programs do not necessarily include systematic quality improvement initiatives; they rely primarily on each hospital to develop their own programs to advance their report card ratings. ${ }^{11}$

The fourth approach, adopted by Providence, ${ }^{1}$ combines centralized governance and accountability with systematic performance improvement initiatives. The national paradigm is the Veterans Affairs cardiac surgery quality program, begun in the early 1970s. ${ }^{12}$ In the Veterans Affairs program, a central committee monitors the performance of each program, identifies quality concerns, and may require program remediation or even closure. At Providence, strategic and tactical decisions are made at the system level by a multidisciplinary committee. ${ }^{1}$ Surgeons lead these efforts at their own hospitals, but the central governance structure organizes system-wide improvement initiatives and enforces accountability. Principal strategies include routine sharing of identified institutional and surgeon-level data; standardization of quality improvement processes with checklists; regular morbidity and mortality conferences with phase of care mortality analysis of all deaths; and annual outcomes targets with identification and analysis of outlying programs, which are expected to submit nonpunitive corrective action plans with specific actions, metrics, leaders, and timelines.

In the study of Worrall and colleagues, ${ }^{1}$ this highly structured, system-wide approach to improvement achieved results quickly, efficiently, and at scale, but some caution is 
warranted. Behavioral science studies suggest that professionals performing highly complex tasks may be most effectively motivated by internal drivers, such as the desire to achieve and be recognized for their mastery, to exercise greater autonomy in their actions, and to have a clear sense of purpose. ${ }^{13}$ As applied to cardiac surgery improvement, this motivational pattern suggests that a centralized governing authority should set realistic targets and provide specific improvement recommendations and support while giving frontline leaders and staff the autonomy to "own" the processes at their institutions and to be fully accountable for their results. At least in the Veterans Affairs and Providence systems, this approach has yielded impressive results. A strong case can be made that this level of centralized oversight is an ethical responsibility of large systems with numerous cardiac surgery centers.

\section{References}

1. Worrall N, Brevig J, Jin R, Gluckman T, Hunter R, Ducsik M, et al. Reduction in coronary artery bypass grafting surgery mortality and morbidity during a 3-year multicenter quality improvement project. J Thorac Cardiovasc Surg. 2020;159:1779-91.

2. ElBardissi AW, Aranki SF, Sheng S, O’Brien SM, Greenberg CC, Gammie JS. Trends in isolated coronary artery bypass grafting: an analysis of the Society of Thoracic Surgeons adult cardiac surgery database. J Thorac Cardiovasc Surg. 2012;143:273-81.
3. Osborne NH, Nicholas LH, Ryan AM, Thumma JR, Dimick JB. Association of hospital participation in a quality reporting program with surgical outcomes and expenditures for Medicare beneficiaries. JAMA. 2015;313: 496-504.

4. Etzioni DA, Wasif N, Dueck AC, Cima RR, Hohmann SF, Naessens JM, et al. Association of hospital participation in a surgical outcomes monitoring program with inpatient complications and mortality. JAMA. 2015;313:505-11.

5. Berwick DM. Measuring surgical outcomes for improvement: was Codman wrong? JAMA. 2015;313:469-70.

6. Malenka DJ, O'Connor GT. A regional collaborative effort for CQI in cardiovascular disease. Northern New England Cardiovascular Study Group. Jt Comm J Qual Improv. 1995;21:627-33.

7. Prager RL, Armenti FR, Bassett JS, Bell GF, Drake D, Hanson EC, et al; Michigan Society of Thoracic and Cardiovascular Surgeons. Cardiac surgeons and the quality movement: the Michigan experience. Semin Thorac Cardiovasc Surg. 2009;21:20-7.

8. Speir AM, Rich JB, Crosby I, Fonner E Jr. Regional collaboration as a model for fostering accountability and transforming health care. Semin Thorac Cardiovasc Surg. 2009;21:12-9.

9. Hannan EL, Kumar D, Racz M, Siu AL, Chassin MR. New York state's cardiac surgery reporting system: four years later. Ann Thorac Surg. 1994;58: 1852-7.

10. Shahian DM, Grover FL, Prager RL, Edwards FH, Filardo G, O’Brien SM, et al The Society of Thoracic Surgeons voluntary public reporting initiative: the first 4 years. Ann Surg. 2015;262:526-35.

11. Chassin MR. Achieving and sustaining improved quality: lessons from New York State and cardiac surgery. Health Aff (Millwood). 2002;21:40-51.

12. Grover FL, Johnson RR, Shroyer AL, Marshall G, Hammermeister KE. The vet erans affairs continuous improvement in cardiac surgery study. Ann Thorac Surg. 1994:58:1845-51.

13. Pink D. Drive: The Surprising Truth About What Motivates Us. New York: Riverhead Books; 2009 